\title{
Influência do consumo de diferentes níveis de Spirulina no desenvolvimento e perfil lipídico de $\operatorname{ratos}^{1}$
}

\author{
Lidiane Moreira Chiattoni ${ }^{* 2}$, Mírian Ribeiro Galvão Machado ${ }^{3}$, Rosane da Silva Rodrigues ${ }^{4}$, \\ Leonor Almeida de Souza Soares ${ }^{5}$ \\ http://dx.doi.org/10.1590/0034-737X201562020003
}

\begin{abstract}
RESUMO
Spirulina é uma cianobactéria que vem sendo produzida e estudada por suas propriedades nutricionais e por seus benefícios à saúde. Neste estudo, avaliou-se a influência de dietas acrescidas de diferentes concentrações de Spirulina sobre o desenvolvimento corporal e o perfil lipídico de ratos. Foram utilizados 24 ratos Wistar, alimentados, durante 40 dias, com quatro dietas isoproteicas (10\%) distintas, sendo seis animais por grupo: 1) Dieta controle (AIN93G adaptada); 2) Dieta S1 (8,8\% de Spirulina); 3) Dieta S2 (17,6\% de Spirulina); 4) Dieta S3 (26,4\% de Spirulina). Foram avaliados parâmetros nutricionais e o perfil lipídico dos animais, cujos dados foram analisados estatisticamente por Análise de Variância, seguida do teste de Tukey, a 5\% de significância ( $\mathrm{p} \leq 0,05)$. O tratamento com 8,8\% de Spirulina mostrou-se equivalente ao controle, apresentando respostas mais adequadas de CEA, medidas de crescimento e lipídios séricos. Já o S2 não foi capaz de promover um bom desenvolvimento corporal, comparado com o do controle, além de elevar os níveis de colesterol total e LDL-c. O tratamento S3 apresentou somente valores estatisticamente diferentes de HDL-c, quando comparado com os do controle ( $\mathrm{p} \leq$ 0,05). Conclui-se que, no tempo e condições do estudo, o tratamento S3, único com Spirulina como fonte exclusiva de proteína, foi capaz de substituir a fonte proteica padrão (caseína) na dieta para roedores, promovendo o adequado desenvolvimento corporal e lipídico dos animais.
\end{abstract}

Palavras-chave: avaliação biológica, efeito metabólico, Rattus norvegicus, lipídios séricos.

\section{ABSTRACT}

\section{Influence of consumption of different levels of Spirulina on the development and lipid profile in rats}

Spirulina is a cyanobacterium that has been produced and studied because of their nutritional properties and health benefits. This study evaluated the influence of diets added with different concentrations of Spirulina on body development and lipid profiles in Wistar rats. The experiment used twenty-four Wistar rats. The animals were fed for 40 days with four different isoprotein diets (10\%), with 6 animals per group: 1) control diet (adapted AIN93G), 2) Diet S1 - (8.8\% Spirulina), 3) S2 diet (17.6\% Spirulina) 4) Diet S3 (26.4\% Spirulina). The study evaluated nutritional parameters and lipid profile of the animals, whose data were statistically compared by analysis of variance, followed by Tukey's test, at significance level of 5\% (p d" 0.05). Treatment with 8.8\% of Spirulina was equivalent to control, presenting the most appropriate responses to CEA, growth measures and serum lipids. In

\footnotetext{
Submetido em 02/08/2012 e aprovado em 13/03/2015.

${ }^{1}$ Este trabalho é parte da dissertação da primeira autora.

${ }^{2}$ Universidade Federal do Rio Grande, Programa de Pós-graduação em Engenharia e Ciência de Alimentos, Rio Grande, Rio Grande do Sul, Brasil. lidianemunizmoreira@ yahoo.com.br

${ }^{3}$ Universidade Federal de Pelotas, Centro de Ciências Químicas, Farmacêuticas e de Alimentos, Pelotas, Rio Grande do Sul, Brasil. miriangalvão@gmail.com

${ }^{4}$ Universidade Federal de Pelotas, Centro de Ciências Químicas, Farmacêuticas e de Alimentos, Pelotas, Rio Grande do Sul, Brasil. rosane.rodrigues@ufpel.edu.br

5 Universidade Federal do Rio Grande, Programa de Pós-graduação em Engenharia e Ciência de Alimentos, Rio Grande, Rio Grande do Sul, Brasil. leonor.souzasoares@gmail.com

"Autor para correspondência: lidianemunizmoreira@yahoo.com.br
}

Rev. Ceres, Viçosa, v. 62, n.2, p. 142-148, mar-abr, 2015 
contrast, $\mathrm{S} 2$ was not able to promote good body development, compared to the control, in addition to increasing the levels of total cholesterol and LDL-c. Treatment S3 showed only statistically different values of HDL-C compared to control $(\mathrm{p} \leq 0.05)$. It was concluded that during the time and conditions of the study, treatment $\mathrm{S} 3$, the only one with Spirulina as the sole source of protein, was able to replace the standard source of protein - casein - in the diet of rodents, promoting the adequate development of body and lipids in the animals.

Key words: biological assay, metabolic effect, Rattus norvegicus, serum lipids.

\section{INTRODUÇÃO}

Microalgas são fontes economicamente viáveis de proteína para uso na alimentação (Colla et al., 2008), com destaque para a cianobactéria Spirulina (Arthrospira), que contém cerca de 60 a $70 \%$ de proteínas, cujos aminoácidos encontram-se em teores próximos aos recomendados como padrão pela FAO (Food and Agriculture Organization). Contêm ainda betacaroteno, ferro absorvível, além de outros minerais e altos níveis de vitaminas, ácido gama-linolênico e outros ácidos graxos essenciais (Belay et al.,1993; FDA, 2012). Tem sido bastante estudada também, por causa da presença de ficocianina e compostos fenólicos os quais the conferem atividade antioxidante, frequentemente associada à capacidade de redução de hiperlipidemias (Alves et al., 2005; Colla et al., 2008; Bertolin et al., 2009). Atualmente, no Brasil, a Spirulina é classificada como novo ingrediente e seu consumo diário, recomendado pela Agência Nacional de Vigilância Sanitária (ANVISA), é de $1.6 \mathrm{~g}$ /indivíduo (Brasil, 2009). Segundo Becker (2007), entre os fatores que limitam o uso de microalgas na alimentação humana está a presença da parede celular, que pode influenciar na digestibilidade e absorção e, ainda, o alto conteúdo de ácidos nucleicos, cuja ingestão em excesso pode levar ao seu acúmulo no organismo humano e, consequentemente, a doenças como gota e cálculo renal. A partir do consumo diário de Spirulina (1.6 g/indivíduo) preconizado pela ANVISA, estabeleceu-se o objetivo desta pesquisa, que foi avaliar a influência de dietas acrescidas de diferentes concentrações de Spirulina LEB-18 no desenvolvimento corporal e no perfil lipídico de ratos Wistar.

\section{MATERIAL E MÉTODOS}

\section{Biomassa microalgal}

A microalga utilizada neste trabalho foi a Spirulina da cepa LEB-18/FURG, isolada da Lagoa Mangueira. Sua produção é realizada na Planta Piloto localizada às margens da Lagoa Mangueira (3330' $13^{\prime \prime} \mathrm{S}$ e $53^{\circ} 08^{\prime} 59^{\prime}$
W), em Santa Vitória do Palmar, RS. A unidade consiste de três tanques abertos, tipo raceway, de $10.000 \mathrm{~L}$ e de um tanque aberto, tipo raceway, de $1.000 \mathrm{~L}$ para propagação do inóculo. Os cultivos são protegidos por túnel de filme transparente com proteção contra raios UV e expostos a condições ambientais naturais. Quando a microalga atinge a concentração de 0,50 g. $\mathrm{L}^{-1}$, sua biomassa é separada por meio de filtração e secada em secador de bandejas, a $50{ }^{\circ} \mathrm{C}$, por $5 \mathrm{~h}$ (Morais et al.,2008).

\section{Modelos biológicos}

Para realização do estudo, 24 Rattus norvegicus da cepa Wistar, machos, recém desmamados (21 dias), com peso médio de $70 \mathrm{~g}$, provenientes do Biotério da Universidade Federal de Pelotas(UFPel), RS, Brasil, foram distribuídos aleatoriamente em grupos $(n=6)$ e alojados individualmente em gaiolas de arame galvanizado. Estes animais foram mantidos durante cinco dias para adaptação às condições laboratoriais (fase de pré-experimento). Após este período, os animais foram pesados e redistribuídos, conforme a massa corporal, em quatro grupos homogêneos (Berndtson, 1991): C ( $=6)$, S1 (n $=6), S 2(n=6), S 3(n=6)$.

\section{Dietas}

Seguindo as determinações do Instituto Americano de Nutrição (American Institute of Nutrition), o qual publicou em 1993 a fórmula de uma dieta para ratos em crescimento (AIN-93G, growingrats) (Reeves et $a l ., 1993)$, foram preparadas semanalmente no Laboratório de Processamento de Alimentos da UFPel quatro dietas (Tabela 1): dieta controle (C) (AIN93G adaptada); dieta S1 (8,8\% de Spirulina); dieta S2 (17,6\% de Spirulina) e dieta S3 (26,4\% de Spirulina). A formulação da dieta C, apesar da recomendação de $20 \%$ de ingestão de proteína pela AIN-93G, foi calculada para apresentar 10\% deste nutriente (Miller \& Bender, 1955; Sgarbieri, 1996; Jood \& Singh, 2001). Para obtenção desta dieta $\mathrm{C}$, com $10 \%$ de proteína, foram adiciona- 
dos 120 g de caseína, já que essa não se apresentava pura (> 85\% de proteína), o restante dos ingredientes, conforme preconizado por Reeves et al. (1993), e o amido de milho adicionado para completar $1000 \mathrm{~g}$ de dieta. Para formulação das dietas S1, S2 e S3, o cálculo foi baseado na composição proximal da biomassa e na quantidade de ingestão diária recomendada para roedores (20 g/rato/dia) (Souza-Soares et al., 2009) e no limite estabelecido pela ANVISA como consumo máximo diário de Spirulina (1,6 g/indivíduo/dia) (Brasil, 2009).

\section{Experimento in vivo}

O experimento foi realizado durante 40 dias, período em que o laboratório permaneceu sob condições de luz (fotoperíodo de $12 \mathrm{~h}$ ) e temperatura $\left(22 \pm 2^{\circ} \mathrm{C}\right)$ controladas, como também sob renovação de ar por sistema de exaustão.

\section{Determinação dos parâmetros ponderais}

As dietas foram ofertadas diariamente (20 g/rato), assim como a pesagem da ração não consumida, obtendo-se o valor de ingesta diária. Os pesos dos animais foram registrados semanalmente para cálculo do ganho de peso. Após os 40 dias experimentais, os animais foram avaliados biometricamente, por meio do peso corporal final (g), comprimento vértice-cóccix, comprimento dos membros torácicos e medida da circunferência abdominal (cm).

\section{Análise química da biomassa, dietas e fezes}

A composição proximal da biomassa e das dietas foi determinada conforme métodos descritos pela Association of Official Analytical Chemists (AOAC, 1995), com exceção de lipídios totais, os quais foram determinados por método de Bligh \& Dyer (1959), também utilizado para avaliação de lipídios nas fezes.

\section{Avaliação nutricional}

Foram realizadas as seguintes determinações para avaliação da qualidade das dietas em estudo: Coeficiente de Eficácia Alimentar (CEA), dado pela razão entre o ganho de peso e a quantidade total de dieta ingerida durante o experimento; e Digestibilidade Lipídica Aparente (DL), obtida por meio do cálculo: [lipídio ingerido lipídio excretado nas fezes/lipídio ingerido]100 (Sgarbieri, 1996).

\section{Análise bioquímica do soro}

Ao término do experimento, os animais foram submetidos a um jejum de 12 horas e eutanasiados. Alíquotas de sangue foram coletadas e centrifugadas a $1000 \mathrm{~g}$ x 15 min, a $4{ }^{\circ} \mathrm{C}$, em tubos de ensaio para obtenção do soro, o qual foi congelado a $-18^{\circ} \mathrm{C}$ e, posteriormente, analisado em avaliador bioquímico LabMax 240 (LABTEST DIAGNÓSTICA S.A.) quanto aos teores de colesterol total, LDL-colesterol (lipoproteína de baixa densidade), HDL-colesterol (lipoproteína de alta densidade), VLDLcolesterol (lipoproteína de baixíssima densidade) e triacilgliceróis.

A execução do experimento foi aprovada pela Comissão de Ética em Experimentação Animal da UFPel, RS, Brasil (processo no 23110. 008077/2009-22), em conformidade com as normas do Colégio Brasileiro de Experimentação Animal - COBEA.

\section{Análise estatística}

Os dados foram avaliados por análise de variância (ANOVA), seguida do teste de Tukey para comparação entre as médias a $5 \%(\mathrm{p} \leq 0,05)$ de significância .

Tabela 1. Formulação das dietas C (Controle), S1 (Spirulina 8,8\%), S2 (Spirulina 17,6\%) e S3 (Spirulina 26,4\%)

\begin{tabular}{|c|c|c|c|c|}
\hline & \multicolumn{4}{|c|}{ Ingredientes $\left(\mathrm{g.kg}^{-1}\right)$} \\
\hline & $\mathbf{C}$ & S11 & $\mathbf{S 2}^{1}$ & S3 \\
\hline $\begin{array}{l}\text { Spirulina LEB-18 ( } 56 \% \text { proteína; } 7,4 \% \text { lipídios; } \\
10,7 \% \text { minerais; } 0,5 \% \text { fibras) }\end{array}$ & - & 88,0 & 176,0 & 264,0 \\
\hline Caseína (> 85\% proteína) & 120,0 & 50,5 & 1,5 & - \\
\hline Óleo de soja & 70,0 & $63,5 *$ & $57,0 *$ & $50,5^{*}$ \\
\hline Mistura de minerais ${ }^{2}$ & 35,0 & $25,5 *$ & $16,0^{*}$ & $6,5^{*}$ \\
\hline Mistura de vitaminas ${ }^{2}$ & 10,0 & 10,0 & 10,0 & 10,0 \\
\hline L- cistina & 3,0 & 3,0 & 3,0 & 3,0 \\
\hline Bitartarato de colina & 2,5 & 2,5 & 2,5 & 2,5 \\
\hline Farelo de trigo & 50,0 & $43,5^{*}$ & $37,0^{*}$ & $30,5^{*}$ \\
\hline Sacarose & 100,0 & 100,0 & 100,0 & 100,0 \\
\hline Amido de milho ${ }^{3}$ & 609,5 & 613,5 & 597,0 & 533,0 \\
\hline
\end{tabular}

${ }^{1}$ Para obtenção de $10 \%$ de proteína, mínimo necessário para desenvolvimento de roedores, as dietas S1 e S2 foram suplementadas com caseína;

${ }^{2}$ Preparado conforme AIN-93G (Reeves et al., 1993);

${ }^{3}$ Adicionado para completar a dieta;

* Descontado valor intrínseco presente na microalga. 


\section{RESULTADOS E DISCUSSÃO}

Verifica-se (Tabela 2) que o grupo S3 não diferiu do grupo $\mathrm{C}$ relativamente a todos os parâmetros ponderais e nutricionais avaliados. Da mesma forma, o grupo $\mathrm{S} 1$, apesar de apresentar menor consumo que $\mathrm{C}(\mathrm{p} \leq 0,05)$, resultou em parâmetros ponderais e nutricionais semelhantes, estatisticamente ( $\mathrm{p}>0,05)$, ao grupo controle $(\mathrm{C})$, indicando ser também sua formulação uma boa fonte proteica. Já o grupo S2 apresentou valores de peso final, ganho de peso total, consumo alimentar total, vértice-cóccix, circunferência abdominal e coeficiente de eficiência alimentar inferiores $(\mathrm{p} \leq 0,05)$ aos do grupo $\mathrm{C}$.

De acordo com Vieira \& Bion (1998), proteínas originadas de diferentes misturas e usadas em diferentes proporções podem resultar em variações nas concentrações de aminoácidos limitantes, os quais interferem na eficiência de sua utilização pelo homem e pelos animais. Rogatto et al. (2004) analisaram uma dieta com $17 \%$ de Spirulina, em substituição total à proteína da dieta controle (caseína), em ratos machos jovens Wistar durante cinco semanas e obtiveram CEA de 0,21 , valor este semelhante ao que se encontrou nos tratamentos com 17,6 e $26,4 \%$ de Spirulina (0,23 e 0,22; respectivamente).

Proteínas de menor qualidade ou combinação de diferentes proteínas que apresentam deficiências em aminoácidos essenciais serão, preferencialmente, destinadas a vias metabólicas de catabolismo. Após a degradação no trato gastrintestinal das proteínas ingeridas em seus aminoácidos, estes alcançam o fígado através da corrente sanguínea. Chegando ao fígado, o primeiro passo no catabolismo dos aminoácidos é a remoção dos grupos amino, por ação de transaminases, resultando na formação de glutamato e de unidades de três e quatro átomos de carbonos ( $\alpha$-cetoácidos). Estes esqueletos carbônicos provenientes da desaminação dos aminoáci- dos são convertidos em glicose, por meio da gliconeogênese, a qual poderá ser utilizada para suprir as necessidades energéticas das células ou para ser armazenada na forma de ácidos graxos, por meio do metabolismo hepático (Devlin, 2007).

A hiperlipidemia caracteriza-se por uma série de distúrbios ocasionados pelo excesso de substâncias, dentre estas o colesterol, triacilgliceróis e lipoproteínas do plasma sanguíneo, como HDL (lipoproteína de alta densidade), LDL (lipoproteína de baixa densidade) e VLDL (lipoproteína de densidade muito baixa), sendo um importante fator de risco no desenvolvimento de doenças cardíacas e de arteriosclerose. Na Tabela 3, observa-se que o grupo $\mathrm{S} 1$ não diferiu do $\mathrm{C}$ em todos os parâmetros bioquímicos avaliados; já o S2 apresentou níveis de colesterol total e de LDL-c e LDL/HDL mais elevados $(\mathrm{p} \leq 0,05)$ que $\mathrm{C}$; enquanto o $\mathrm{S} 3$ resultou em HDL-c inferior e LDL/HDL maior que $\mathrm{C}(\mathrm{p} \leq 0,05)$.

Se for tomado como referência o valor médio de colesterol total (46 mg.dL ${ }^{-1}$ ), em Rattus norvegicus sadios descrito por Mitruka \& Rawnsley (1981), os tratamentos S1 e S3 apresentam as melhores respostas. Vilela et al.(2000), ao avaliarem os níveis séricos de lipídios em ratos Wistar com 21 dias, sob ação de uma dieta com extrato proteico de leveduras em substituição à caseína, constataram que esta (58 mg.dL ${ }^{-1}$ de colesterol total) se comportou semelhantemente ao controle com caseína (60 mg.dL ${ }^{-1}$ de colesterol total). Denardin et al. (2009) encontraram 62,67 e 72,93 mg.dL $\mathrm{dL}^{-1}$ de colesterol total em ratos Wistar alimentados com dieta com arroz e macarrão em substituição à caseína, respectivamente.

Bertolin et al., (2009), autores que estudaram o efeito da S.platensis no perfil lipídico de ratos Wistar, não encontraram alteração significativa ao tratar os animais com dieta hipercolesterolêmica, acrescida de Spirulina, por 60 dias, sugerindo que a microalga associada a uma

Tabela 2. Respostas ponderais e nutricionais de ratos Wistar alimentados por 40 dias com as dietas C (controle), S1 (8,8\% Spirulina), S2 (17,6\% Spirulina) e S3 (26,4\% Spirulina)

\begin{tabular}{lcccc}
\hline \multirow{2}{*}{ Determinação } & \multicolumn{4}{c}{ Tratamentos } \\
\cline { 2 - 5 } & $\mathbf{C}$ & $\mathbf{S 1}$ & $\mathbf{S 2}$ & $\mathbf{S 3}$ \\
\hline PI $(\mathrm{g})^{*}$ & $70,65 \pm 11,15^{\mathrm{a}}$ & $70,33 \pm 7,10^{\mathrm{a}}$ & $68,33 \pm 8,80^{\mathrm{a}}$ & $73,65 \pm 7,10^{\mathrm{a}}$ \\
PF $(\mathrm{g})$ & $253,33 \pm 27,35^{\mathrm{a}}$ & $263,65 \pm 20,00^{\mathrm{a}}$ & $200,35 \pm 19,25^{\mathrm{b}}$ & $232,65 \pm 14,50^{\mathrm{ab}}$ \\
GPT $(\mathrm{g})$ & $182,65 \pm 35,00^{\mathrm{a}}$ & $175,33 \pm 20,90^{\mathrm{a}}$ & $134,33 \pm 14,05^{\mathrm{b}}$ & $156,15 \pm 15,75^{\mathrm{ab}}$ \\
CAT $(\mathrm{g})$ & $622,10 \pm 22,30^{\mathrm{a}}$ & $573,45 \pm 26,60^{\mathrm{b}}$ & $575,85 \pm 30,25^{\mathrm{b}}$ & $654,25 \pm 24,00^{\mathrm{a}}$ \\
VC $(\mathrm{cm})$ & $20,85 \pm 0,80^{\mathrm{a}}$ & $20,98 \pm 0,35^{\mathrm{a}}$ & $19,60 \pm 0,85^{\mathrm{b}}$ & $20,25 \pm 0,80^{\mathrm{ab}}$ \\
MT $(\mathrm{cm})$ & $13,30 \pm 0,65^{\mathrm{ab}}$ & $13,35 \pm 0,40^{\mathrm{b}}$ & $12,55 \pm 0,40^{\mathrm{a}}$ & $13,15 \pm 0,40^{\mathrm{ab}}$ \\
CA $(\mathrm{cm})$ & $16,10 \pm 1,05^{\mathrm{a}}$ & $16,00 \pm 1,85^{\mathrm{a}}$ & $13,95 \pm 0,65^{\mathrm{b}}$ & $14,95 \pm 1,15^{\mathrm{ab}}$ \\
CEA & $0,28 \pm 0,05^{\mathrm{ab}}$ & $0,32 \pm 0,04^{\mathrm{a}}$ & $0,23 \pm 0,04^{\mathrm{b}}$ & $0,22 \pm 0,03^{\mathrm{b}}$ \\
DL & $78,25 \pm 3,55^{\mathrm{a}}$ & $75,60 \pm 3,50^{\mathrm{a}}$ & $69,45 \pm 3,55^{\mathrm{a}}$ & $75,25 \pm 3,70^{\mathrm{a}}$ \\
\hline ME & &
\end{tabular}

Média \pm desvio padrão; letras distintas em uma mesma linha indicam diferença significativa pelo teste de Tukey ( $\leq \leq 0,05)$;

*Depois de 5 dias de adaptação;

PI: peso inicial; PF: Peso final; GPT: Ganho de peso total; CAT: consumo alimentar total; VC: vértice-cóccix; MT: membros torácicos; CA: circunferência abdominal; CEA: coeficiente de eficácia alimentar; DL: digestibilidade lipídica aparente. 
dieta rica em colesterol não altera os níveis lipídicos. Segundo Miller (1993), a fração LDL-c deve representar cerca de dois terços (2/3) do valor do colesterol total, fato esse ocorrido nos animais do grupo S2, no qual, apesar do colesterol total estar elevado, os valores de LDL-c aumentaram proporcionalmente.

Bertolin et al.(2009) não avaliaram os níveis de LDLc individualmente e, sim, em somatório ao valor de VLDL-c, obtendo 60,1 mg.dL-1 . Ao se somarem os resultados obtidos de LDL-c e VLDL, neste estudo, são encontrados os seguintes valores: 39,$75 ; 36,15 ; 54,71$ e 40,61 mg.dL $\mathrm{dL}^{-1}$ para C, S1, S2 e S3, respectivamente. Estes valores, quando calculados os seus percentuais em relação ao do colesterol total, mostram índices de 56,7\% (dieta controle), 56,0\% (S1), 61,6\% (S2) e 62,8\% (S3) em relação aos mesmos, indicando uma resposta mais harmônica entre as dietas. Esses dados assemelham-se aos obtidos por Bertolin et al., (2009) para dietas fornecidas durante 30 e 60 dias, respectivamente, que foram 61,5 e 76,7\% (controle), 34,6 e 69,5\% (hiperlipídica com $5 \%$ de colesterol) e 41,8 e $60,7 \%$ (hiperlipídica com 5\% de Spirulina), indicando, nas respostas, o efeito da duração do experimento e que a presença de Spirulina na dieta hiperlipêmica, em função deste, não foi efetiva. Evidenciam, também, a tendência hiperlipêmica das dietas contendo caseína.

Na patogênese da aterosclerose, a lipoproteína de alta densidade (HDL-c) apresenta um importante papel protetor, pois transporta o excesso de colesterol das artérias e da corrente sanguínea até o fígado, onde é metabolizado e eliminado sob a forma de ácidos e sais biliares (Duarte et al.,2009). Na Tabela 3, observa-se que o tratamento com maior percentual de Spirulina (S3) resultou em níveis de HDL-c inferiores $(\mathrm{p} \leq 0,05)$ ao controle. Bertolin et al., (2009) encontraram níveis de HDL-c igual a $12,3 \mathrm{mg} \cdot \mathrm{dL}^{-1}$, nos animais do grupo controle, e $32,3 \mathrm{mg} \cdot \mathrm{dL}^{-1}$, nos animais alimentados com dieta hipercolesterêmica acrescida de Spirulina.

De forma semelhante ao que foi relatado, anteriormente, em relação aos valores de colesterol total, os dados para colesterol HDL deste trabalho, quando con- siderados seus percentuais, indicam 43,5\% (C), 43,6\% (S1), 36,5\% (S2) e 36, 6\% (S3), assemelhando-se aos dados de Bertolin et al. (2009), que foram, respectivamente, de 38,9 e $19,7 \%$ (controle), 56,7 e $27,5 \%$ (hiperlipídica) e 45,6 e 32,5\% (hiperlipídica $+5 \%$ de Spirulina). Estes valores, quando calculados os seus percentuais em relação aos de colesterol total, mostram índices de 56,7\% (C), 56,0\% (S1), 61,6\% (S2) e 62,8\% (S3). No estudo de Vilela et al. (2000), uma dieta com extrato proteico de leveduras em substituição à caseína comportou-se semelhantemente $\left(45 \mathrm{mg} . \mathrm{dL}^{-1}\right)$ àquela com caseína (50 mg.dL ${ }^{-1}$ ), quanto ao teor de HDL-c presente no soro de ratos Wistar.

Embora ainda não tenha sido determinada a relação LDL/HDL ideal para roedores e o valor estipulado para humanos não possa ser utilizado diretamente, convenciona-se que esta relação deva ser a menor possível para indicar uma característica benéfica. O grupo S1 não diferiu do controle na relação LDL/HDL, ambos apresentando valores mais baixos $(\mathrm{p} \leq 0,05)$ que os grupos S2 e S3. Contudo, todas as dietas acrescidas de Spirulina bem como a dieta controle resultaram em valores superiores aos encontrados por Silva (2009), de 0,43 e $0,30 \mathrm{mg} \cdot \mathrm{dL}^{-1}$, em ratos fêmeas Wistar alimentados com as dietas controle e experimental (leite caprino), respectivamente.

Triacilgliceróis são os lipídios presentes em maior quantidade na alimentação e constituem a forma de armazenamento de todo o excesso de nutrientes, seja carboidrato, proteína ou o próprio lipídio, representando a maior reserva energética dos mamíferos (Devlin, 2007). Os tratamentos não diferiram entre si quanto aos níveis de triacilgliceróis, sendo estes apresentados numa faixa de 66,35 a 78,00 mg.dL ${ }^{-1}$. De acordo com dados preconizados pela equipe do Centro de Bioterismo da Faculdade de Medicina da Universidade de São Paulo (FMUSP, 2010), triacilgliceróis devem estar presentes no soro de Rattus norvegicus sadios em torno de 66,35 a 78,0 mg.dL ${ }^{-1}$. Apesar de não ter havido diferença estatística entre os grupos, observa-se que o tratamento S3, o qual apresenta Spirulina como fonte exclusiva de pro-

Tabela 3. Respostas bioquímicas de ratos Wistar alimentados por 40 dias com dietas C (controle), S1 (8,8\% Spirulina), S2 (17,6\% Spirulina) e S3 (26,4\% Spirulina)

\begin{tabular}{|c|c|c|c|c|}
\hline \multirow{2}{*}{ Determinação(mg.dL $\left.{ }^{-1}\right)$} & \multicolumn{4}{|c|}{ Tratamentos } \\
\hline & $\mathbf{C}$ & S1 & S2 & S3 \\
\hline Colesterol total & $70,15 \pm 8,49^{a}$ & $64,50 \pm 10,83^{a}$ & $88,83 \pm 3,90^{\mathrm{b}}$ & $64,50 \pm 11,15^{a}$ \\
\hline HDL-c & $30,50 \pm 3,70^{\mathrm{a}}$ & $28,15 \pm 3,90^{\mathrm{ab}}$ & $34,16 \pm 1,72^{a}$ & $23,65 \pm 2,33^{\mathrm{b}}$ \\
\hline LDL-c & $23,15 \pm 9,05^{b}$ & $20,65 \pm 12,20^{b}$ & $39,15 \pm 3,15^{\mathrm{a}}$ & $27,35 \pm 4,85^{\mathrm{ab}}$ \\
\hline LDL/HDL & $0,75 \pm 0,30^{\mathrm{a}}$ & $0,70 \pm 0,35^{\mathrm{a}}$ & $1,14 \pm 0,15^{\mathrm{b}}$ & $1,15 \pm 0,20^{\mathrm{b}}$ \\
\hline VLDL-c & $16,60 \pm 6,65^{a}$ & $15,50 \pm 6,15^{\mathrm{a}}$ & $15,56 \pm 4,27^{\mathrm{a}}$ & $13,26 \pm 5,34^{\mathrm{a}}$ \\
\hline Triacilgliceróis & $70,95 \pm 16,55^{\mathrm{a}}$ & $77,50 \pm 30,70^{\mathrm{a}}$ & $78,00 \pm 21,30^{\mathrm{a}}$ & $66,35 \pm 26,75^{\mathrm{a}}$ \\
\hline
\end{tabular}

Média \pm desvio padrão; letras distintas em uma mesma linha indicam diferença significativa pelo teste de Tukey $(\mathrm{p} \leq 0,05)$.

Rev. Ceres, Viçosa, v. 62, n.2, p. 142-148, mar-abr, 2015 
teínas, obteve respostas menores de triacilgliceróis. Já os grupos, que têm como fonte proteica uma mistura de caseína e Spirulina, obtiveram valores maiores de triacilgliceróis que os tratamentos S3 e C.

A utilização da Spirulina como alimento tem sido bastante discutida, pelo fato de ser boa fonte de proteína, vitaminas, minerais e ácidos graxos poli-insaturados (Rogatto et al., 2004; Ambrosi et al., 2008; Moreira et al., 2011). Segundo Colla et al.(2008), a presença de compostos antioxidantes, como ficocianina, compostos fenólicos, e ácidos graxos poli-insaturados pode ser a principal responsável pela diminuição dos níveis lipídicos. A capacidade antioxidante de extratos de Spirulina foi avaliada por Miranda et al. (1998) no plasma de ratos Wistar adultos, os quais receberam uma dose diária de $5 \mathrm{mg} / \mathrm{dia}$ do extrato por 2 e 7 semanas. Os autores consideraram que as quantidades de ácidos fenólicos, $\alpha$-tocoferol e $\beta$-caroteno, presentes na Spirulina, foram responsáveis pela redução dos níveis lipídicos dos animais.

\section{CONCLUSÃO}

As diferentes concentrações de Spirulina cepa LEB$18(8,8,17,6$ e 26,4\%) influenciaram diferentemente o desenvolvimento corporal e os níveis bioquímicos determinados em ratos Wistar. O tratamento com $8,8 \%$ de Spirulina mostrou-se equivalente ao controle, apresentando respostas mais adequadas de CEA, medidas de crescimento e lipídios séricos. Já o S2 não foi capaz de promover um bom desenvolvimento, comparativamente ao controle, além de elevar os níveis de colesterol total e LDL-c, enquanto S3 apresentou somente valores inferiores de HDL-c, quando comparado ao controle ( $\mathrm{p} \leq$ 0,05). Assim, conclui-se que, no tempo e condições deste estudo, o tratamento S3, único com Spirulina como fonte exclusiva de proteína, foi capaz de substituir a fonte proteica padrão (caseína) na dieta para roedores, mostrando-se adequada para o desenvolvimento corporal e lipídico dos animais.

\section{AGRADECIMENTOS}

Os autores agradecem ao projeto PRÓ-ENGENHARIA, da CAPES, pela bolsa de mestrado concedida.

\section{REFERENCIAS}

Alves CR, Voltarelli FA \& Mello MAR (2005) Spirulina as a protein source in the recovery of undernourished rats: effect on skeletal muscle. Revista Digital de Educación Física y Deportes. Disponível em: <http://www.efdeportes.com/efd86/spirulin.htm>. Acessado em: julho de 2012.

Ambrosi MA, Reinehr CO, Bertolin TE, Costa JAV \& Colla LM (2008) Propriedades de saúde de Spirulina spp. Revista de Ciências Farmacêuticas Básica e Aplicada, 29:109-117.
AOAC - Association of Official Analytical Chemists (1995) Official methods of analysis. $16^{\mathrm{a}} \mathrm{ed}$. Washington, AOAC International. 1094p.

Becker EW (2007) Micro-algae as a source of protein. Biotechnology Advances, 25:207-210.

Belay AOY, Miyakawa K \& Shimamatsu H (1993) Currient knowledge on potential health benefits of Spirulina. Journal Applied Phycology, 5:235-241.

Berndtson WE (1991) A simple rapid and reliable method for selecting or assessing the number of replicates for animal experiments. Journal Animal Science, 69:67-76.

Bertolin TE, Pilatti D, Giacomini ACVV, Bavaresco CS, Colla LM \& Costa JAV (2009) Effect of microalga Spirulina platensis (Arthrospira platensis) on hippocampus lipoperoxidation and lipid profile in rats with induced hypercholesterolemia. Brazilian Archives of Biology and Technology, 52:1253-1259.

Bligh EG \& Dyer WJ (1959) A rapid method of total lipid extraction and purification. Canadiam Journal of Biochemistry and Physiology, 37:911-917

Brasil (2009) Alimentos com Alegações de Propriedades Funcionais e ou de Saúde, Novos Alimentos/Ingredientes, Substâncias Bioativas e Probióticos - Lista dos Novos Ingredientes aprovados pela Agência Nacional de Vigilância Sanitária em maio de 2009. Disponível em: <http://www.anvisa.gov.br/legis/index.htm>. Acessado em: 07 de julho de 2012.

Colla ML, Muccilo-Baisch AL \& Costa JAV (2008) Spirulina platensis effects on the levels of total colesterol, HDL and triacylglycerols in rabbits fed with a hypercholesterolemic diet. Brazilian Archives of Biology and Technology, 51:405-411.

Denardin CC, Boufleur N, Reckziegel P \& Silva LP (2009) Influência do consumo de arroz ou de macarrão no desempenho e resposta metabólica em ratos. Alimentos e Nutrição, 20:441-449.

Devlin TM (2007) Textbook of biochemistry - with clinical correlations. São Paulo, Edgard Blucher. 1186p.

Duarte SMS, Abreu CMP, Menezes HC, Paula FBA, Pereira RGFA \& Gouvea CMCP (2009) Peeled coffee brew effect in the antioxidant activity hematological and biochemical parameters in rats. Ciência e Tecnologia de Alimentos, 29:703-708.

FDA (2012) Foodand Drug Administration. Disponível em: <http:// ww w.fda.gov/Food/FoodIngredient s Packaging/ GenerallyRecognizedasSafeGRAS/GRASListings/ucm153674.htm>. Acessado em: 07 de julho de 2012.

FMUSP (2010) Biotery Center School of Medicine. University of São Paulo. Disponível em: 〈http:www.biot.fm.usp.br/site1/index-2.html〉. Acessado em: 13 de outubro de 2010.

Jood S \& Singh M (2001) Amino acid composition and biological evaluation of the protein quality of high lysine barley genotypes. Plant Foods Human Nutritional, 56:145-155.

Miller DS \& Bender AE (1955) The determination of the net protein utilization of proteins by a hortened method. Britsch Journal Nutritional, 9:382-388.

Miller O (1993) Laboratório para o clínico. Rio de Janeiro, Atheneu. 493p.

Miranda MS, Cintra RG, Barros SBM \& Filho JM (1998) Antioxidant activity of the microalga Spirulina maxima. Brazilian Journal of Medical and Biological Research, 31:1075-1079.

Mitruka MB \&Rawnsley HM (1981) Clinical, biochemical and hematological reference values in normal experimental animals and normal humans. New York, Masson Publishing. 314p.

Morais MG, Reichert CC, Dalcanton F, Durante AJ, Marins LFF \& Costa JAV (2008) Isolation and characterization of a new Arthrospira strain. Zeitschrift für Naturforschung, 63:144-150. 
Moreira LM, Rocha ASR, Ribeiro CLG, Rodrigues RS \& Souza-Soares LA (2011) Nutritional evaluation of single-cell protein produced by Spirulinaplatensis. African Journal of Food Science, 5:799-805.

Reeves PG, Nielsen FH \& Fahey JR (1993) AIN-93 Purified Diets for Laboratory Rodents: Final Report of the American Institute of Nutrition Ad Hoc Writing Committee on the Reformulation of the AIN-76 Rodent Diet. Journal of Nutrition, 123:1939-1951.

Rogatto GP, Oliveira CAM, Santos JW, Machado F, Nakamura FY, Moraes C, Zagatto AM, Faria MC, Afonso M \& Mello MAR (2004) Influence of Spirulina intake on metabolism of exercised rats. Revista Brasileira de Medicina do Esporte, 10:258-263.

Sgarbieri VC (1996) Proteínas em alimentos protéicos: propriedades, degradação, modificação. São Paulo, Editora e Livraria Varela. 517p.
Silva PV (2009) Leite caprino: caracterização físico-química, perfil de ácidos graxos e avaliação biológica (ratos fêmeasWistar). Tese de Doutorado. Universidade Federal de Pelotas, Pelotas. 146p.

Souza-Soares LA, Machado MRG \& Rodrigues RS (2009) Experimentação com animais de laboratório: manual básico. Pelotas, Editora Universitária. $468 \mathrm{p}$

Vieira RL \& Bion FM (1998) Biological value of diet based on soybean (Glycine hispid) and mesquite (Prosopis juliflora). Boletim Ceppa, 16:85-98.

Vilela ESD, Sgarbieri VC \& Alvim ID (2000) Nutritive value of biomass of integral cells, autolisate and extract and yeast cells from beer. Revista de Nutrição, 16:127-134. 